American Journal of Environmental Sciences 6 (2): 103-114, 2010

ISSN 1553-345X

(C) 2010 Science Publications

\title{
Evaluation of the Groundwater Global Pollution Risk: Relationships with Territorial Planning
}

\author{
${ }^{1}$ M. De Maio, ${ }^{2}$ F. Minucci and ${ }^{1}$ G. Nocerino \\ ${ }^{1}$ Department of Land, Environment and Geo-Engineering, Politecnico di Torino, \\ Corso Duca Degli Abruzzi 24, 10129 Torino, Italy \\ ${ }^{2}$ Department of Inter, University Territorial Studies and Planning, Politecnico di Torino, \\ Castello del Valentino, Viale Mattioli 39, 10125 Torino, Italy
}

\begin{abstract}
Problem statement: The protection and enhancing of Groundwater Resources (GWR) at an international level have been studied extensively, but they have very rarely been considered in Territorial Planning and Urban Planning. Now more than in the past, thanks to the technologies and know-how acquired over the years, ignoring responsibilities with regards to the close link between these themes is no longer possible, therefore a new research field has been introduced that will lead to a strategic approach, in such a way that GWR and economic and urban planning development will be able to co-exist. Approach: This study, through the application of the Holman and Groundwater Global Pollution Risk methods, is an attempt to link these two topics. Results: The study was conducted in Aosta, a town in the north-west of Italy, in an attempt to assess the effects that a careless management of the setting up of polluting activities could have on the aquifers. Conclusion: The analysis was carried out using a Geographical Information System (GIS).
\end{abstract}

Key words: GWR protection and enhancement, Holman method, global risk evaluation, strategic planning, strategic environmental evaluation (VAS), structural plan, operative plan

\section{INTRODUCTION}

The proposed work deals with a portion of the Aosta Valley, a region in the north-west of Italy, which is over $8 \mathrm{~km}$ long and $40 \mathrm{~km}$ wide and has a roughly quadrilateral shape (Fig. 1). The Valley borders on France, Switzerland and the Piedmont Region.

The investigated area is within the perimeter of the city of Aosta and it encompasses the Aosta plain and the flat part of land that ends at the Montjovet gorge.

The Table 1 lists the main directives and laws, with reference to the three legislative levels (European Community, National and Regional), for the study area considered.

Table 1: Directives and Laws pertaining to the protection and enhancement of GWR

\begin{tabular}{|c|c|c|}
\hline E community level & National level & Regional level \\
\hline $\begin{array}{l}\text { Framework directive } \\
\text { No. } 2000 / 60 / \text { EC }\end{array}$ & L No. $183 / 89$ & RL 27/99 \\
\hline $\begin{array}{l}\text { Directive } \\
\text { No. } 91 / 271 / \mathrm{EC}\end{array}$ & L No. $36 / 94$ & RL 59/82 \\
\hline Directive 98/83/EC & $\begin{array}{l}\text { L No. 152/99 } \\
\text { Title V reform of the } \\
\text { Italian constitution: } \\
\text { Principle of subsidiarity }\end{array}$ & $\begin{array}{l}\text { Territorial landscaping } \\
\text { plan } \\
\text { Water protection plan }\end{array}$ \\
\hline
\end{tabular}

\section{MATERIALS AND METHODS}

The aim of this study was to carry out a qualitative deterioration analysis of the groundwater, through the calculation of pollution risk in relationship to two different situations:

- The first, which takes into account the risk generated by a single, Defined Hazard Centre (DHC) (Civita, 1990; Civita et al., 2005) or Diffused Hazard Source (DHS) (Pfannkuch, 1990; Foster and Hirata, 1988) on the territory and its resources; in this case, the Holman method (Holman, 1958) was used to carry out the analysis. This method is used to obtain an immediate decision-making instrument for emergencies and it can be used to set the basis for subsequent, more in-depth analyses which instead use a more territorial type approach

- The second, which takes the Groundwater Global Pollution Risk (Civita and De Maio, 1997) into account, that is, the pollution generated by the presence of multiple and different DHC and/or DHS over an extensive territory, in relation to the water resources and, consequently, the population supplied

Corresponding Author: M. De Maio, Department of Land, Environment and Geo-Engineering, Politecnico di Torino, Corso Duca degli Abruzzi 24, 10129 Torino, Italy Tel: +39 0115647685 
The Holman method consists of an accurate survey of the DHC and DHS in the study area. As far as the involved space, it is concerned to distinguish the punctual DHC (e.g., a seeping tank) from the general ones, or DHS (e.g., a plot of land cultivated with agrochemicals). On the basis of accurate statistics, it is possible to highlight the activities that most frequently cause groundwater pollution and to draw up a potential hazard list.

It is necessary to assess the different Hazard and Control Factors for each DHC, whether natural or man made, which determine or prevent groundwater pollution.

For each of the aforementioned factors, a weight has been set in a 1-3 range $(1=$ low hazard; $2=$ medium hazard; $3=$ high hazard), so that the following can be calculated:
- The Hazard Factor Index (HFI), that is, the product of the weights and the hazard factors (Table 2):

$$
\mathrm{HFI}=\mathrm{A} \times \mathrm{B} \times \mathrm{C} \times \mathrm{D}
$$

- The Control Factor Index (CFI), that is, the product of the weights and the control factors (Table 3):

$$
\mathrm{CFI}=\mathrm{E} \times \mathrm{F} \times \mathrm{G}
$$

It is therefore possible to calculate the Hazard Index (HI) of each hazard centre (Table 4) as:

$$
\mathrm{HI}=\mathrm{HFI} \times \mathrm{CFI}
$$

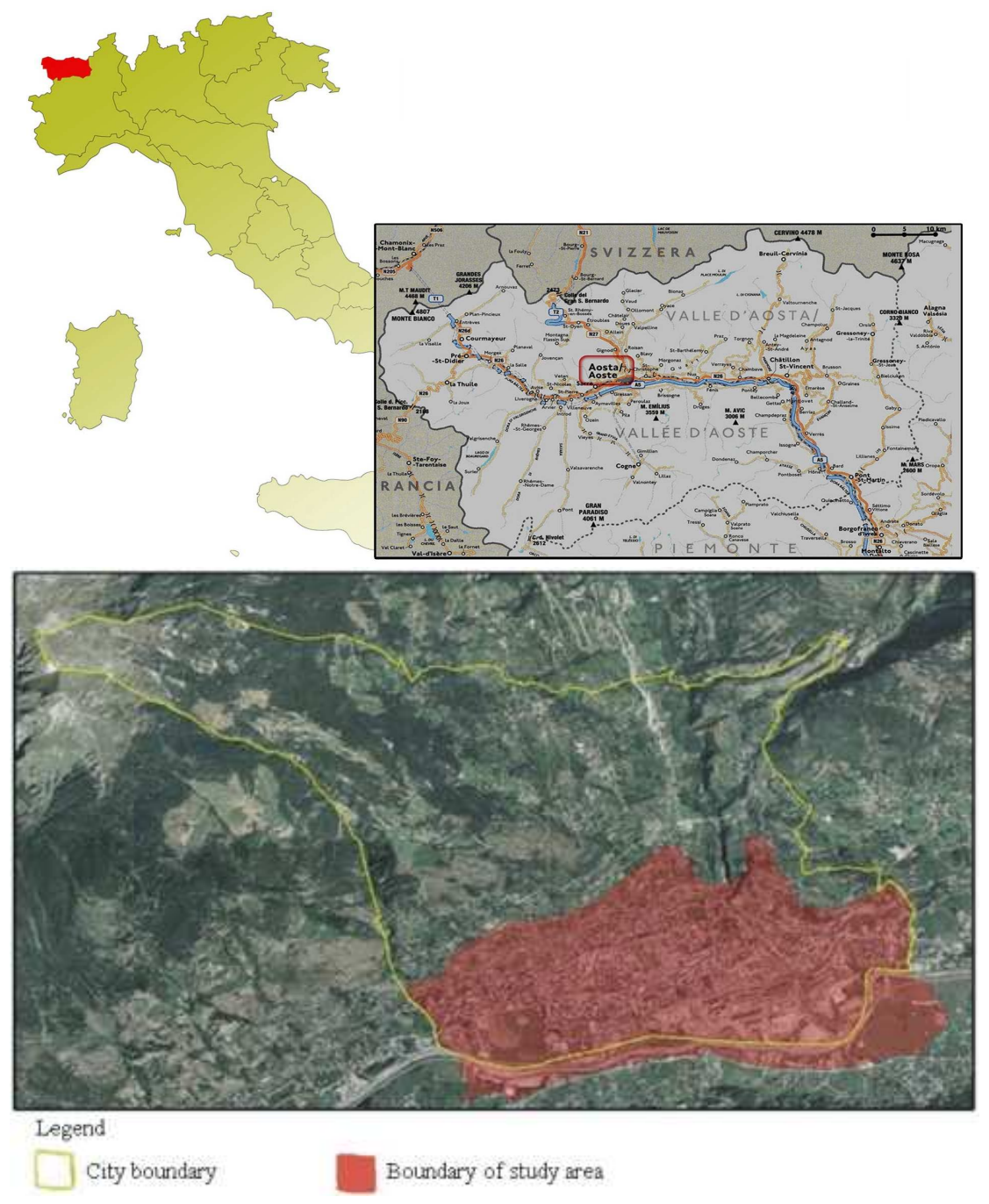

Fig. 1: Localization of study area 
Am. J. Environ. Sci., 6 (2): 102-114, 2010

Table 2: Calculation of the Hazard Factor Index (HFI)

\begin{tabular}{lll}
\hline Code & Description & Weight \\
\hline A & Potential toxicity of discharged pollutants: & \\
& Toxic chemicals & 3 \\
& Pathogenic bacteria and viruses & 2 \\
& Materials affecting taste, flavor or color & 1 \\
B $\quad$ Potential concentration of discharged pollutants: & \\
& High concentration $(50-100 \%)$ & 3 \\
& Moderate concentration $(10-50 \%)$ & 2 \\
& Low concentration $(<10 \%)$ & 1 \\
C $\quad$ Potential polluting load: & 3 \\
& $>501 / \mathrm{m}^{2} /$ day & 2 \\
& $10-501 / \mathrm{m}^{2} /$ day & 1 \\
D & Pol $1 / \mathrm{m}^{2} /$ day & 3 \\
& Potential frequency of discharging pollutants: & \\
& $30-365$ day/year & 2 \\
& $8-30$ day/year & 1 \\
\hline
\end{tabular}

Table 3: Calculation of the Control Factor Index (CFI)

\begin{tabular}{lll}
\hline Code & Description & Weight \\
\hline $\mathrm{E}$ & Degree of natural protection: & \\
& Discharge in the underlying aquifer system & 3 \\
& Discharge in the soil & 2 \\
& Discharge on the soil surface & 1 \\
$\mathrm{~F}$ & Degree of preventive control of the hazard centre: & 3 \\
& Poor & 2 \\
& Modest & 1 \\
$\mathrm{G}$ & Elevated & \\
Relative distance to the closest polluting subject: & \\
& The hazard centre is on the upstream gradient & 3 \\
& $<1 \mathrm{~km}$ & 2 \\
& $1-3 \mathrm{~km}$ & 1 \\
& $>3 \mathrm{~km}$ & 3 \\
& The hazard centre is on the downstream gradient & \\
& $<0.5 \mathrm{~km}$ & 2 \\
$0.5-1 \mathrm{~km}$ & 1 \\
\hline & $>1 \mathrm{~km}$ &
\end{tabular}

Table 4: Hazard Index values range

Impact

potential Low $\quad$ Moderate High $\quad$ Very high

$\begin{array}{lllll}\text { HI } & 1 \leq \mathrm{IP} \geq 546 & 547 \leq \mathrm{IP} \geq 1093 & 1094 \leq \mathrm{IP} \geq 1640 & 1641 \leq \mathrm{IP} \geq 2187\end{array}$

The system is used to analyze two different hazard levels, one linked to the possibility of the pollution of a water point by a DHC and the other which is generated by the synergic action, on the GWR, of different DHCs of the same type and which assumes a level of pollution that makes them unsuitable for human supply.

A comparison between the calculated HI leads to the definition of a priority list where a low HI means a low pollution hazard for a specific water point in the long term and a high $\mathrm{HI}$ implies a high hazard in the short term.

The calculation of the Territorial Hazard Index (THI) is carried out by multiplying the average HI value, expressed in thousands, related to each homogeneous DHC group surveyed, by the product of the assumed release surface (which is calculated in hectares) and the number of DHC that make up the homogeneous surveyed group:
$\mathrm{THI}=(\mathrm{HI}$ average $/ 1000) \times \mathrm{S}[\mathrm{ha}] \times \mathrm{N}$ hazard centers

The groundwater global pollution risk method, apart from weighing the single sources of pollution, considers the territory in which these are located. In order to do this, each source is assigned a reference Pollution Hazard Index (PHI), which identifies their potential hazard; subsequently, considering the tapping wells of the water supply system as Subjects at Risk (SaR), the Vulnerability of the Subjects to Risk $\left(\mathrm{Vu}_{\mathrm{sar}}\right)$ is calculated together with the Value of the Subjects at $\operatorname{Risk}\left(\mathrm{Va}_{\mathrm{sar}}\right)$.

Considering the innumerable variables that have to be accounted for, the PHI, which was developed within the framework of the European Union COST 620 Action (AAVV, 2004), takes into account the quantitative and qualitative aspects involved in the procedure of establishing the weight to assign to the single activities (Table 5); 7 factor types have been identified.

Each factor has a weight that varies from 0-3, according to the impact it has on the specific activity. When the factor is 0 , it is not present, in relation to the specified activity and the entity of the overall hazard is determined by summarizing the score.

In order to calculate the $\mathrm{Vu}_{\mathrm{sar}}$ and $\mathrm{Va}_{\mathrm{sar}}$ of the $\mathrm{SaR}$, two distinct diagonal matrices are utilized.

The first matrix, which refers to $\mathrm{Vu}_{\mathrm{sar}}$, is derived from the crossing of:

- The Intrinsic Vulnerability degree, which is expressed though the SINTACS Index (Table 6)

- The Exposure Level (Table 7), which is calculated from:

- The distance of the well from the neighboring DHC

- The position of these (DHC), in relation to the aquifer flow direction (hydraulic gradient)

- The hydrogeological characteristics of the aquifer (hydraulic conductivity of the aquifer)

At this point, the $\mathrm{Vu}_{\mathrm{SAR}}$ can be calculated on the basis of the crossing of the Intrinsic Vulnerability and the exposure, by applying the diagonal matrix (Table 8):

$$
\mathrm{Vu}_{\mathrm{SAR}}=\mathrm{D}(\text { VSINTACS, LE })
$$

The second matrix, which refers to $\mathrm{Va}_{\mathrm{SAR}}$, is obtained by crossing, in a specific matrix of values:

- The Basic Quality (Table 9), which expresses whether the resource is naturally scarce and impacted or of good quality 
Table 5: Hazard factor typologies

\begin{tabular}{|c|c|c|}
\hline Hazard factor type & Description & SFP range \\
\hline Special substances & $\begin{array}{l}\text { The activity generates waste and/or refuse that can be classified as special waste as provided } \\
\text { for by Part } 4 \text { of Italian Leg. Dec 152/2006 }\end{array}$ & $0-3$ \\
\hline Dangerous substances & $\begin{array}{l}\text { The activity generates waste and/or refuse that can be classified as dangerous waste as provided } \\
\text { for by Part } 4 \text { of Italian Leg. Dec 152/2006, or other harmful substances }\end{array}$ & $0-3$ \\
\hline Water waste organic pollutants & The activity generates waste water characterized by a mainly organic type pollution & $0-3$ \\
\hline Water waste inorganic pollutants & The activity generates waste water characterized by a mainly inorganic type pollution & $0-3$ \\
\hline $\begin{array}{l}\text { Handling and/or storing of } \\
\text { potentially hazardous materials }\end{array}$ & $\begin{array}{l}\text { The activity implies the storage of materials classifiable as dangerous waste as provided for by } \\
\text { Part 4of Italian Leg. Dec 152/2006, or other harmful substance that could damage the GWR }\end{array}$ & $0-3$ \\
\hline Water-demanding activities & The activity's productive cycle calls for the utilization of considerable quantities of water & $0-3$ \\
\hline Area or linear pollution & The activity implies a potential, diffused type of pollution (involving an area) & $0-3$ \\
\hline
\end{tabular}

Source: Tacconi and Zavatti (1999), modified

Table 6: Intrinsic vulnerability values range

\begin{tabular}{lll}
\hline Intrinsic vulnerability & & SINTACS \\
Index & Level & Index (\%) \\
\hline Vi 1 & Very low & $0-24$ \\
Vi 2 & Low & $25-35$ \\
Vi 3 & Medium & $36-49$ \\
Vi 4 & High & $50-69$ \\
Vi 5 & Elevated & $70-79$ \\
Vi 6 & Extremely elevated & $80-100$ \\
\hline
\end{tabular}

Table 7: Exposure values range

\begin{tabular}{lll}
\hline $\begin{array}{l}\text { Exposure } \\
\text { Index }\end{array}$ & Level & $\begin{array}{l}\text { Distance travelled by the flow } \\
\text { (m/60 days) }\end{array}$ \\
\hline L 1 & Very low & 0.5 \\
L 2 & Low & 5 \\
L 3 & Medium & 50 \\
L 4 & Elevated & 500 \\
\hline
\end{tabular}

Table 8: $\mathrm{Vu}_{\mathrm{SAR}}$ range of values

\begin{tabular}{lllllll}
\hline Exposure & & & & & \multicolumn{2}{c}{ Vulnerability Index } \\
Index & Vi 1 & Vi 2 & Vi 3 & Vi 4 & Vi 5 & Vi 6 \\
\hline L 1 & 1 & 1 & 1 & 2 & 3 & 4 \\
L 2 & 1 & 1 & 2 & 3 & 4 & 5 \\
L 3 & 1 & 2 & 3 & 4 & 5 & 6 \\
L 4 & 2 & 3 & 4 & 5 & 6 & 6 \\
\hline
\end{tabular}

Table 9: Quality values range

Quality of groundwater

Index Level Description

$\mathrm{Q}_{1} \quad$ Poor $\quad$ Water not suitable for human consumption without treatment and limited use for other purposes.

$\mathrm{Q}_{2} \quad$ Medium Water suitable for human consumption but with limitations for irrigation and industrial use

$\mathrm{Q}_{3} \quad$ Excellent Water to be destined for human consumption and for all other uses

- The relative value (Table 10), which is defined on the basis of the classes of the number of Equivalent Inhabitants (EI) supplied

At this point, on the basis of the crossing of the basic quality and the relative value, $\mathrm{Va}_{\mathrm{SAR}}$ can be calculated by applying the diagonal matrix (Table 11):

$$
\mathrm{Va}_{\mathrm{SAR}}=\mathrm{D}(\mathrm{Q}, \mathrm{Vr})
$$

Table 10: Relative values range

\begin{tabular}{lll}
\hline \multicolumn{2}{l}{ Relative value } \\
Index & Level & Description \\
\hline Vr 4 & $\begin{array}{l}\text { Very } \\
\text { elevated }\end{array}$ & $\begin{array}{l}\text { Well, field-wells, spring which feeds or can feed } \\
\text { settlements with AE }>50,000\end{array}$ \\
Vr 3 & Elevated & $\begin{array}{l}\text { Well, field-wells, spring which feeds or can feed } \\
\text { settlements with AE between } 50,000 \text { and } 10,000\end{array}$ \\
Vr 2 & Medium & $\begin{array}{l}\text { Well, field-wells, spring which feeds or can feed } \\
\text { settlements with AE between } 10,000 \text { and } 1,000\end{array}$ \\
Vr 1 & Poor & $\begin{array}{l}\text { Well, field-wells, spring which feeds or can feed } \\
\text { settlements with AE }<1,000\end{array}$ \\
& &
\end{tabular}

Table 11: $\mathrm{Va}_{\text {sar }}$ range of values

\begin{tabular}{lllcc}
\hline Quality & & & \multicolumn{2}{c}{ Relative value Index } \\
Index & Vr 1 & Vr 2 & Vr 3 & Vr 4 \\
\hline $\mathrm{Q}_{1}$ & 1 & 1 & 1 & 2 \\
$\mathrm{Q}_{2}$ & 1 & 1 & 2 & 3 \\
$\mathrm{Q}_{3}$ & 2 & 2 & 3 & 3 \\
\hline
\end{tabular}

\begin{tabular}{ll} 
Table 12: Classes of risk & \\
\hline Range & Degree of pollution risk \\
\hline $1-13$ & Very low \\
$13-23$ & Low \\
$23-31$ & Medium \\
$31-45$ & High \\
$45-60$ & Elevated \\
$60-100$ & Extremely elevated \\
\hline
\end{tabular}

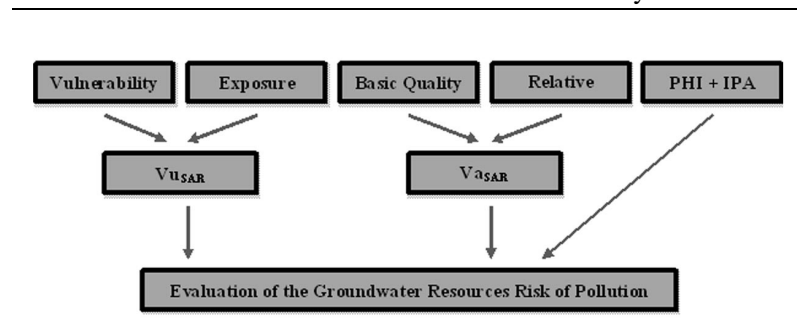

Fig. 2: Flow chart of GWR pollution risk method

In order to calculate the groundwater global pollution risk, it is necessary to multiply the values of $\mathrm{Vu}_{\mathrm{SAR}}, \mathrm{Va}_{\mathrm{SAR}}$ and PHI by each other (Fig. 2), in order to obtain a range which identifies the levels of pollution risk levels.

Table 12 shows the 6 risk classes that were defined in relation to a range of scores for each class. 


\section{RESULTS}

In order to apply the methods outlined in the previous section, a Database was set up, composed of:

- Maps of the study area on a Technical Regional Map (TRC), at a scale of 1:5,000

- Surveys of the activities that generate the greatest risks

- Surveys of the wells tapped for agriculture and drinking water purposes

The data processing was carried out in the Geographical Information System (GIS) environment.

Application of the Holman method (Fig. 3) the weights relative to HFI and CFI were assigned for the HI calculation, as specified in Table 2 and 3. The following types of activity were identified and their relative release surfaces were estimated (Table 13).

The formula (1) was utilized for the THI calculation.

In the Holman analysis, the "probability factor" has a particularly high weight. In the weight calculation of HFI and CFI, it was necessary to assume an accidental risk of discharge during the activities; two reference situations were therefore processed, i.e., a "critical" and a "normal" one and different weights were assigned to the single factors that make up the HI.

The activity of a dry cleaners is shown as an example in Table 14.
The application of the Holman model results in three distinct situations in relation to the two formulated hypotheses:

- Categories of activities which present a low HI in both hypotheses. These consist of car-wash services, copy services, car repair workshops and body repair workshops, hospitals, clinical laboratories (veterinary) and metal work firms

- Dry cleaners and cemeteries, instead, present a moderate HI, but only in situations defined as "critical", whereas in "normal" situations they have a low index

- Fuel storage deposits, underground fuel tanks and service stations present a moderate or elevated HI in both cases

Therefore, from the application of the Holman method, no particular activities emerge that present a risk of pollution, excepting for the activities listed in point 3 .

Table 13: Activity types and relative release areas

\begin{tabular}{llll}
\hline Type of activity & Area (ha) & Type of activity & Area (ha) \\
\hline Car repairs & 0.050 & Electrom. firms & 0.050 \\
Car washes & 0.040 & Metal work firms & 0.020 \\
Dairies & 0.030 & Laundries/Dry clean. & 0.020 \\
Typing agencies & 0.008 & Hospitals & 1.300 \\
Fuel storages & 0.030 & Clinic./veterinary lab. & 0.035 \\
Underground fuel tanks & 0.100 & Cemeteries & 2.600 \\
Service stations & 0.100 & & \\
\hline
\end{tabular}

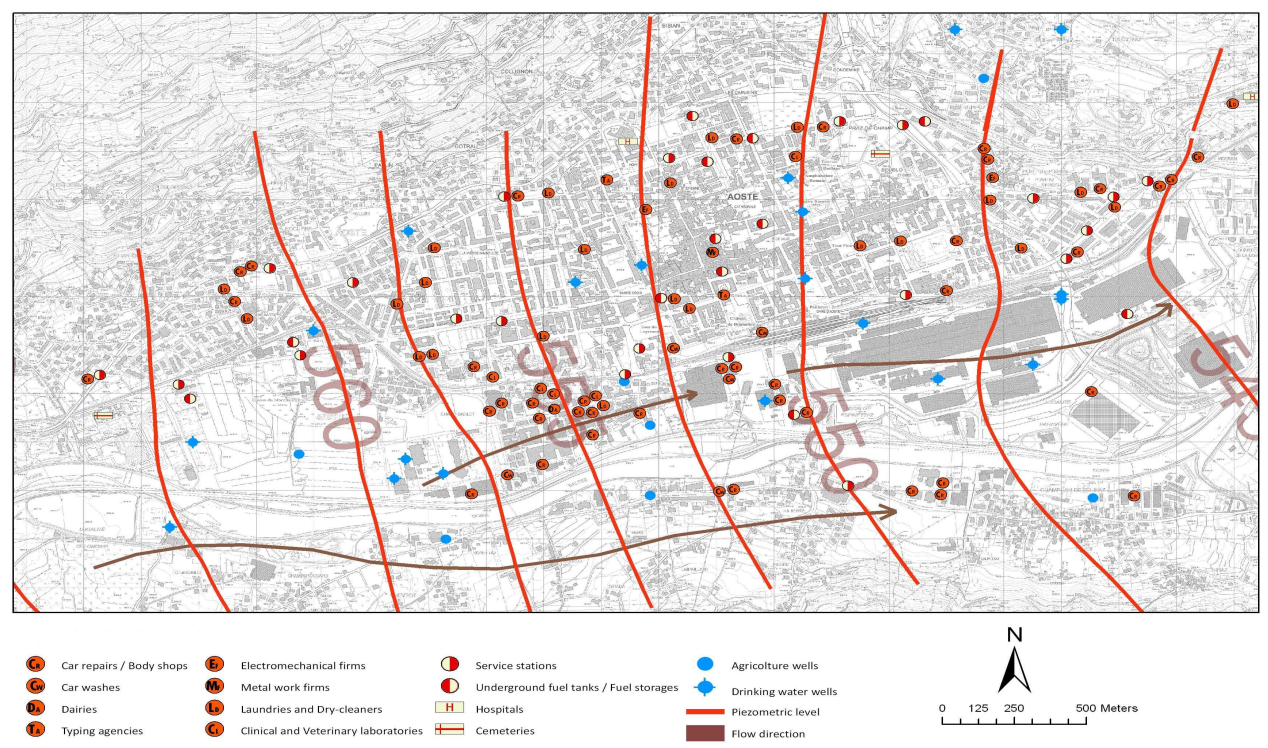

Fig. 3: Localization of human activities-application of the Holman method 
Am. J. Environ. Sci., 6 (2): 102-114, 2010

Table 14: Example of an HI attributed to dry cleaners activities

\begin{tabular}{|c|c|c|c|c|}
\hline \multicolumn{3}{|c|}{ High $\mathrm{HI}=729$} & \multirow[t]{2}{*}{ Risk } & \multirow[t]{2}{*}{ Low $\mathrm{HI}=72$} \\
\hline & Type & f activity: Dry cleaners & & \\
\hline & Code & Description & Weight & Motivation \\
\hline \multirow{4}{*}{$\begin{array}{l}\text { Hazard } \\
\text { factors }\end{array}$} & $\mathrm{A}$ & Potential toxicity of the discharged pollutants & 3 & Toxic chemicals \\
\hline & $\mathrm{B}$ & Potential concentration of discharged pollutants & 3,2 & $\begin{array}{l}\text { The concentration of the pollutants can be elevated or modest } \\
\text { according to the detergents used }\end{array}$ \\
\hline & $\mathrm{C}$ & Potential polluting load & 3,2 & $\begin{array}{l}\text { The polluting load can be considered elevated or moderate in } \\
\text { relation to the activity's operating level }\end{array}$ \\
\hline & $\mathrm{D}$ & Potential frequency of the discharging pollutants & 3,1 & $\begin{array}{l}\text { The frequency can change depending on the probability of an } \\
\text { accident happening or not }\end{array}$ \\
\hline \multirow[t]{3}{*}{$\begin{array}{l}\text { Control } \\
\text { factors }\end{array}$} & $\mathrm{E}$ & Degree of natural protection & 1 & $\begin{array}{l}\text { It is always elevated since, should a spillage occur, this would } \\
\text { be within the premises, with a nil or almost nil level of } \\
\text { pollution risk. It would be a different case if the spillage } \\
\text { should occur in the store where the pollutant is kept }\end{array}$ \\
\hline & $\mathrm{F}$ & Degree of preventive control of the hazard centre & 3,2 & $\begin{array}{l}\text { Depending on the type of premises in which the activity is } \\
\text { being carried out, it could be poor or modest }\end{array}$ \\
\hline & G & Relative distance to the closest polluting subject & 3 & Parameter calculated per single activity \\
\hline
\end{tabular}

Table 15: Comparison of fuel service stations

\begin{tabular}{llllllllllr}
\hline ACTIVITY & A & B & C & D & E & F & G & HFI & CFI & HI \\
\hline Service station 1 & 3 & 3 & 3 & 1 & 3 & 2 & 3 & 27 & 18 & 486 \\
Service station 2 & 3 & 3 & 1 & 3 & 3 & 3 & 3 & 27 & 27 & 729 \\
Service station 3 & 3 & 3 & 3 & 3 & 3 & 3 & 3 & 81 & 27 & 2187 \\
Service station 4 & 3 & 3 & 2 & 3 & 3 & 3 & 3 & 54 & 27 & 1458 \\
Service station 5 & 3 & 3 & 1 & 3 & 3 & 3 & 3 & 27 & 27 & 729 \\
Service station 6 & 3 & 3 & 2 & 3 & 3 & 3 & 3 & 54 & 27 & 1458 \\
Service station 7 & 3 & 3 & 3 & 3 & 3 & 3 & 3 & 81 & 27 & 2187 \\
Service station 8 & 3 & 3 & 2 & 1 & 3 & 2 & 3 & 18 & 18 & 324 \\
Service station 9 & 3 & 3 & 2 & 3 & 3 & 3 & 3 & 54 & 27 & 1458 \\
Service station 10 & 3 & 3 & 2 & 3 & 3 & 3 & 3 & 54 & 27 & 1458 \\
Service station 11 & 3 & 3 & 2 & 1 & 3 & 2 & 3 & 18 & 18 & 324 \\
Service station 12 & 3 & 3 & 3 & 1 & 3 & 2 & 2 & 27 & 12 & 324 \\
Service station 13 & 3 & 3 & 2 & 3 & 3 & 3 & 2 & 54 & 18 & 972 \\
Service station 14 & 3 & 3 & 3 & 3 & 3 & 3 & 3 & 81 & 27 & 2187 \\
\hline
\end{tabular}

On the basis of the result obtained from the HI, two conclusions can be drawn:

- It is possible to understand which activity categories present the greatest risk of pollution

- It is possible to understand, within a certain group, which activities present a greater risk than others. In order to understand this more clearly, an example is proposed: taking the table of service stations into consideration (Table 15), the activities that concern creating a greater risk of pollution for the aquifer can be highlighted. For example, service station 3 presents a very elevated HI compared to station 12

In fact, if parameter $\mathrm{C}$ (Potential polluting load) is very elevated for both activities, parameters $\mathrm{D}$ and $\mathrm{F}$ are substantially different, since the two tanks were sunk at very different times: the former in the sixties-eighties and the latter towards the end of the nineties.

It follows that, should a quality analysis return a poor result due to the presence of pollutants (hydrocarbons), environmental engineers would be inclined to carry out further analyses at the site that is presumed to be a source of pollution.

By analyzing the THI parameter, it is also possible to understand which activities present the greatest risk by relating them to the territory within which they are situated. Even in this case, there is a marked difference between the various groups of classified activities. Practically all the "commercial or craftsman" activities present an THI that does not exceed 1 (considering the situation as "critical"), since the pollutant release areas are relatively modest. The situation foreseen for fuel stores, underground fuel tanks and service stations which have a release area of between 0.1 and $0.3 \mathrm{ha}$, is instead different and thus defines a risk of:

- 1.33 for fuel stores

- 0.92 for underground fuel tanks

- 7.33 for service stations

It is in fact the service stations that represent the greatest hazard for the GWR polluting risk, since they are present in large numbers and are often equipped with obsolete tanks.

Application of the groundwater global pollution risk evaluation method: the evaluation of the Global Risk was obtained by calculating the PHI, the $\mathrm{Vu}_{\mathrm{SAR}}$ and the $\mathrm{Va}_{\mathrm{SAR}}$.

For the PHI (Fig. 4) calculation, the method developed as part of the European Union COST 620 Action is implemented with the data already utilized for the Holman Method in order to improve the analysis. In this way, the urbanized area presents a PHI of 9, but where activities with a pollution risk are installed, the PHI is assigned a greater value according to the craftsman or industrial activity carried out in that area. 


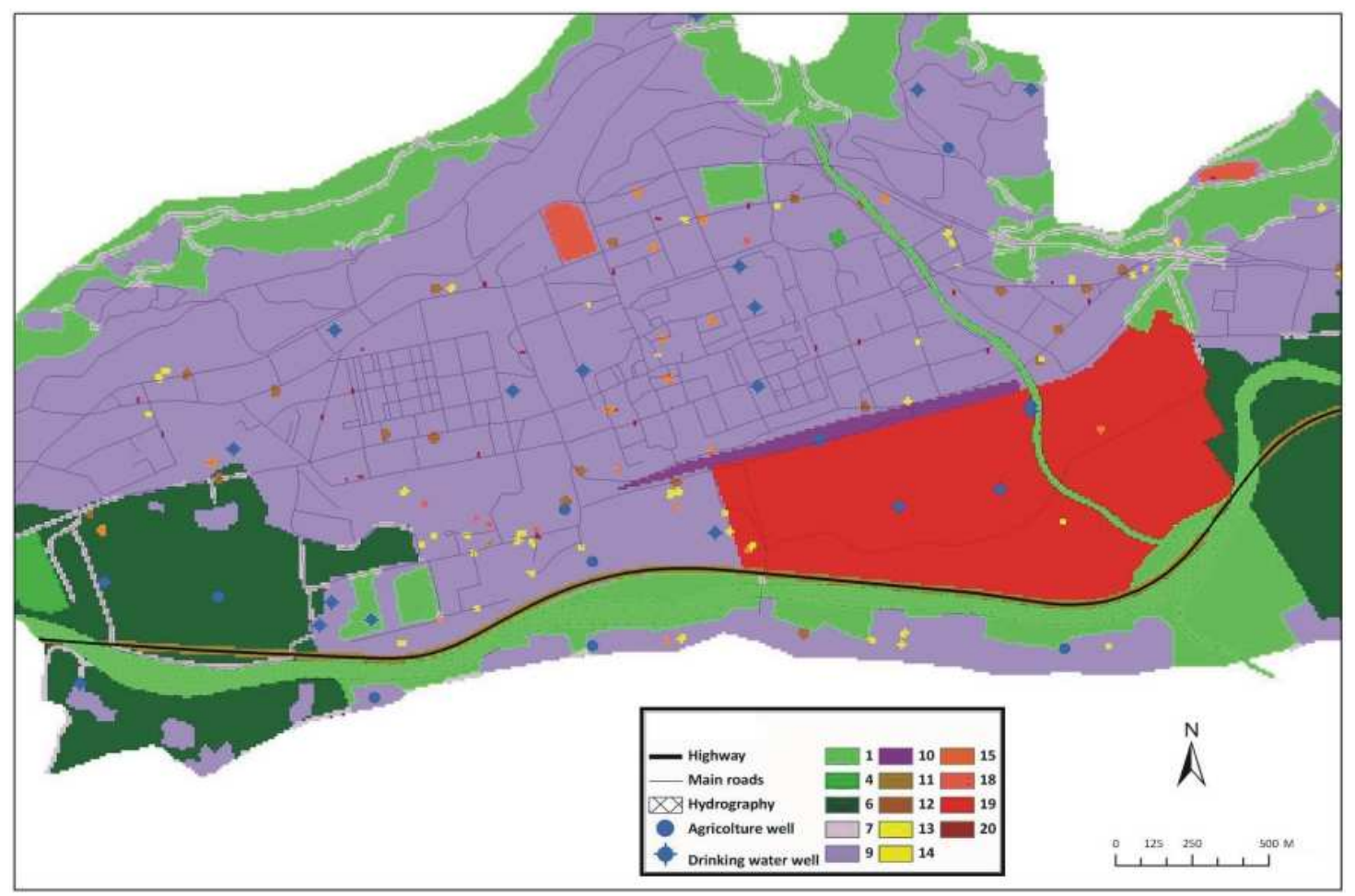

Fig. 4: Pollution Hazard Index (PHI) Map

Table 16: Values of the PHI attributed to the different activities

\begin{tabular}{llll}
\hline & $\begin{array}{l}\text { Pollution } \\
\text { hazard } \\
\text { index }\end{array}$ & Category & $\begin{array}{l}\text { Pollution } \\
\text { hazard } \\
\text { index }\end{array}$ \\
\hline $\begin{array}{l}\text { Category } \\
\begin{array}{l}\text { Hydrography } \\
\text { Cemeteries }\end{array}\end{array}$ & 4 & Typing agencies & 12 \\
& & $\begin{array}{l}\text { Electro-mechanical firms, Car } \\
\text { repair workshops/Body work }\end{array}$ & 13 \\
workshops & \\
Agricultural & 6 & Metal work firms & 14 \\
Municipal roads & 7 & Fuel storage, Car washes & 15 \\
Urbanized & 9 & Hospitals, Clinical laboratories, & 18 \\
Railway & 10 & Industrial & 19 \\
Motorway, Dairies & 11 & Dry cleaners & 20 \\
\hline
\end{tabular}

The activities for which a PHI was identified are shown in Table 16.

In order to build the intrinsic vulnerability map, reference was made to a previous study in which the Vulnerability was evaluated utilizing the "SINTACS R5" Point Count System Model (Civita et al., 2001) which returns a numeric Vulnerability Index of 6 degrees.

The studied area presents a particularly elevated degree of vulnerability which varies from High (Value Vi 4) and Elevated (Value Vi 5), in the Aosta hills, to Extremely Elevated (Value Vi 6), over the whole Plain in which the city of Aosta is located.
The Exposure level map shows an Elevated value (Value L4) for the whole study area.

The $\mathrm{Vu}_{\mathrm{SAR}}$ cartography (Fig. 5), which is made up of the results of the previous analyses, presents values that vary from 6 (Extremely elevated), above all over the whole plain, to 5 in the Aosta hills where the Intrinsic Vulnerability is Elevated.

The basic quality map was built on the basis of the results obtained from the samplings carried out by the Regional Environment Protection Agency (ARPA) and the Politecnico di Torino

The quality was generally reported as good (Value Q3), except for a well within the industrial area, which presents a Poor (value Q1) quality.

The socio-economic value map was plotted by calculating the Equivalent Inhabitants (EI) supplied by the urban water system and the obtained value is extremely elevated (index $\mathrm{Vr} 4$ ).

The $\mathrm{Va}_{\mathrm{SAR}}$ map (Fig. 6) is made up of the previously presented cartographies and the obtained value oscillates between 3 , mainly in the whole Aosta plain and 2, in the area adjacent to the well that indicates Poor quality (Value Q1).

The global pollution risk of the GWR (Fig. 7) cartography is the result of the product of $\mathrm{PHI}, \mathrm{Vu}_{\mathrm{SAR}}$ and $\mathrm{Va}_{\mathrm{SAR}}$. 
Am. J. Environ. Sci., 6 (2): 102-114, 2010

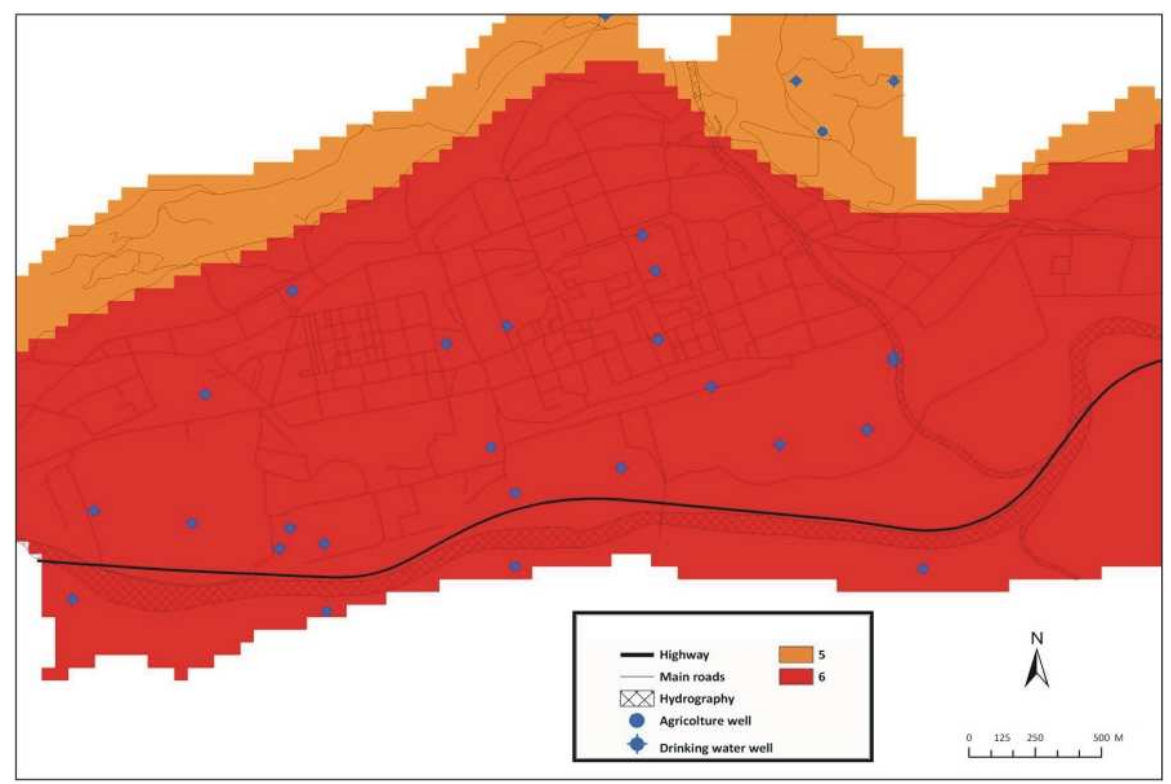

Fig. 5: Vulnerability of Subjects at Risk (SaR)-Vu $\mathrm{U}_{\mathrm{SAR}}$

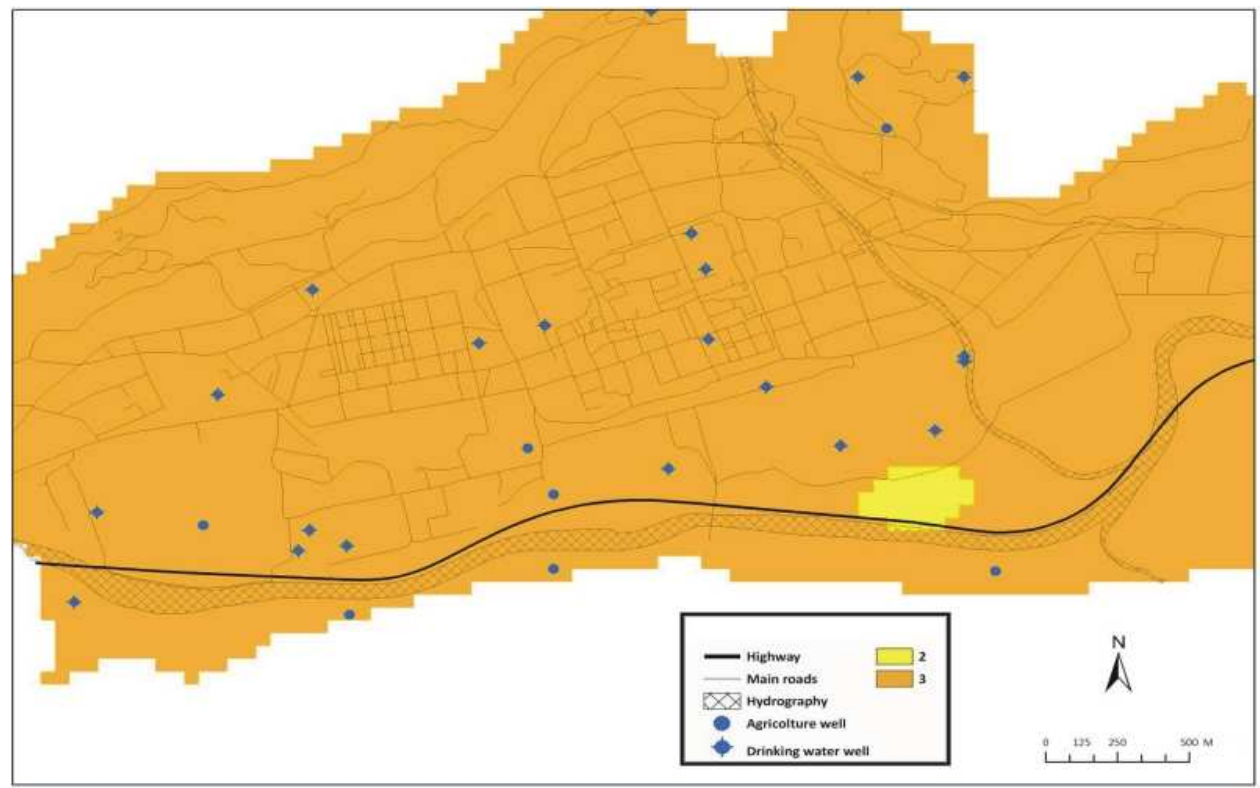

Fig. 6: Value of Subjects at Risk (SaR)-Va $a_{\mathrm{SAR}}$

Two main_classes of risk emerge from the analysis results (in relation to Table 12):

- Elevated or extremely elevated, for the whole urban and industrial area of the city of Aosta

- Low or medium, for the areas surrounding the city, which consist of scattered inhabited settlements or areas that are mainly dedicated to farming or animal husbandry
Nevertheless, some "alarming" situations emerge from a point analysis of the risk classes. The industrial area presents an extremely elevated risk value in relation to three main factors:

- The vulnerability of the aquifer on which the industry has developed is extremely elevated

- The basic quality of the water is elevated (except for one well showing poor quality) 


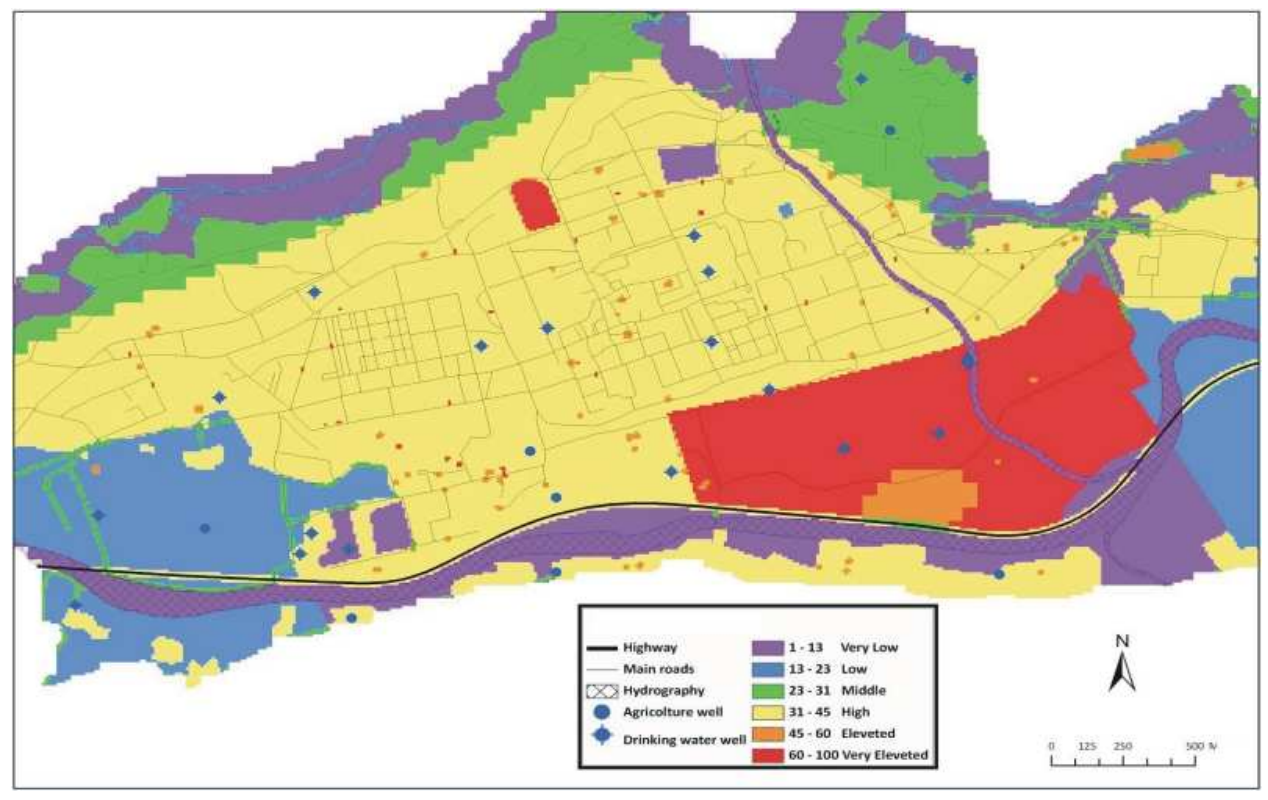

Fig. 7: Groundwater global pollution risk evaluation map

- The pollution hazard index is equal to 20 (very elevated)

The urbanized area in the city of Aosta presents a High level of risk in relation to:

- The pollution hazard index equal to 9

- The vulnerability of the aquifer on which the city is built, which is extremely elevated

In particular, more or less extensive areas can be noted with a level of risk that varies from Elevated to Extremely Elevated. These are areas with economic activities that show a greater pollution risk to which Extremely Elevated PHI values are associated.

\section{DISCUSSION}

The analyses conducted show the need for an integrated approach with the territory planning and management (Wisconsin Groundwater Coordinating Council, 2002; Collin and Melloul, 2001; 2003), which considers all the components associated with it, whether natural or anthropic.

It would be opportune to identify two performance scales relative to the different authorities and responsibilities: a territorial scale and a local one.

At local scale, with reference to GWR, it's necessary to operate through a series of consequent and integrated actions, which should be implemented starting from the planning activities related to town planning transformations. This is in fact the usefulness of the analyses carried out in this research: prevention of deterioration of ecosystems referring to their groundwater component (Haimes, 1984) which depends on the identification, dimensioning and interpretation of the anthropic impacts and loads accumulated and borne by a particular territory.

A definition of the limit-points of the load of urban structures on the environment could lead to a qualitative and quantitative improvement in the GWR quality. This implies drawing up a Dynamic Environmental Report (Part II, Title I, Art. 9, of Italian Law. Dec. number 152, dated April 3, 2006), throw the adoption of an Environmental Accounting System for the entire territory to which a general municipal urban plan refers.

The Environment Consolidation Act (implementing directive 2001/42/EC, concerning the evaluation of the effect of determined plans and programmes on the environment; 85/337/EEC, dealing with the environmental impact evaluation of specified public and private projects, as amended by $97 / 11 / \mathrm{EC}$, 2003/35/EC and 96/61/EC) - Italian Legislative Decree No. 152, dated April 3, 2006, Title II, Chapter I, Art. 7, states that the "Plans and Programmes (...) that (...) could have significant effects on the environment and on the cultural heritage (...), including the “(...)Plans and Programmes that present both the following requisites": "(...) concerning the sectors of agriculture, forestry, fishing, energy, industry, transport, waste and 
water management, telecommunications, tourism, territorial planning or soil use destination are subject to strategic environmental assessment".

In this legislative framework, a Strategic Environmental Assessment that could allow an Environmental Balancing of the pressures generated on the GWR by the anthrophized areas, is legitimized, through an actual Planning that is not only of an Urban Planning nature but also environmental.

It would therefore seem necessary to understand, evaluate and interpret the territory to which the urban planning refers, through the analyses proposed in this study and, if necessary, to implement them in a context of greater deterioration and vulnerability.

In implementing the Urban Governance policy it would therefore seem necessary to consider common shared urban development sustainability (RIVM and RIZA, 1991) objectives through the adoption of "best practices" which should be implemented in the drawing up and application stage of the Structural and Operative Plans.

First, it is necessary to identify the two fields for which it is important to adopt a new approach to the GWR management problem (Foster, 2001; Lashkaripour, 2003):

- The first, for those parts of the city still to be urbanized (expansion areas) and for which it is possible to plan the uses of the soil, compatibly with the GWR

- the second, in the already consolidated parts, for which it is more difficult to implement a strategic approach

In order to implement the aforementioned approaches (Nouri and Malmasi, 2005), it appears indispensable to adopt the Environmental and Social Evaluation procedures related to anthropic impacts on the GWR system, in order to guarantee a balance between the quantity of the urbanized territory and the quality of the urbanization.

\section{"Best practices" for the areas marked for urban expansion:}

- Planning the territory and defining the land use, on the basis of hydrologic principles:

- Planning at a "Catchment area scale": it would be opportune to group together the craftsman and industrial activities with the same land use, compatibly with the environmental needs of the catchment area or drainage basin
- The localizing approach: organize the different homogeneous parts of the territory, so that they interfere with each other as little as possible

- The safeguarding approach: this aims at helping activities at risk to coexist in vulnerable areas. In this case, the perimeter of the area that release pollutants has to be identified, in order to determine the relative safeguarding areas

- An integrated approach to management of the activities in relation to the territory in which they are located:

- Storage and natural treatment of the water in urban expansion areas: in the parts of the territory in which tapping the aquifer causes damage to the environmental system, due to an insufficiency of the GWR, it is possible to:

- Draw water in other areas and transport it by pipe lines

- Set up the tapping of river water which, once returned to the aquifer and subsequently filtered through sand and clay, can then be drawn again

- Treat craftsman and residential wastewater with purifiers, so that it can be reintroduced into the aquifer thus guaranteeing constant recharging of the aquifer

- Guaranteeing adequate storage for the Water Resource, tapping it where it "falls":

- Hold back the water helps to prevent floods: in some parts of the territory, it would be opportune to increase the water storage capacity by building artificial basins that ensure the exploitation of this resource over a period of time

- Keeping a check on excessive underground polluting loads, to assure a high quality of water for the present and for the future:

- Reduce the polluting load in selected areas, particularly where the aquifer is highly vulnerable, by means of appropriate planning or mitigating measures. Reduce subsoil contamination to acceptable levels, considering the vulnerability to pollution of the local aquifer, planning the uses of the ground and introducing selective checks on the DHS

- Planning the drainage water treatment: it would be opportune for the urbanized and industrial areas to be impermeable so that 
pollutants dispersed in the soil are not be transported to the aquifer. It is therefore necessary to set up a system for the collection of rain water that is separate from that of the collection of sewage water from dwellings so that these two components can be separately and specifically treated for each different type of pollutant

- Institutional structure at a social level:

- A solid institutional structure which should rely on legislation that must:

- Clearly and specifically define the water use rights, through the granting of licenses and by imposing taxes on the tapping of groundwater

- Have strong social consensus (therefore avoiding the NYMBY syndrome) concerning the discharge of wastewater in the soil, the availability of land for the construction of waste disposal sites and other potentially contaminating activities

\section{CONCLUSION}

"Best practices" for consolidated urban areas: it is often problematic to apply the "best practices" outlined in the previous paragraph to consolidated urban areas, since the intended land use has already been decided upon and urbanization has already taken place.

It is nevertheless possible to take precautions that could lead to a reduction in pollutants in the aquifer and, at the same time, reduce the risk of discharge in the subsurface, such as:

- Upgrading the wastewater collection system, separating rain from sewage waters, in order to be able to treat them separately and more specifically

- Treatment of wastewater from craftsman and industrial processing and their reintroduction into the aquifer, to guarantee the recharging of the GWR system

- Total impermeabilization of the areas in which activities at greater risk of pollution are carried out and of those in which a situation exists where pollution has continued over the years, in order to avoid transporting pollutants to the aquifer. On the other hand and in general in the areas with a low risk of pollution, it is advisable to guarantee the highest level of permeability possible, to allow the aquifer to recharge and the concentration of the pollutants to be reduced

- In the case in which the water demand is equivalent to the availability of the aquifer, but its exploitation would cause damage to the environmental system, artificial basins should be created for the supply or tapping of water from rivers

- In the areas with greater aquifer vulnerability or where the calculation of GWR global pollution risk method is high, a relocation of the activities at greater risk to pollution should be implemented in favor of portions of land where the Vulnerability index is low or where there is already a preexisting pollution situation. As an alternative, companies can be obliged to carry out a series of structural interventions and checks to guarantee the prevention of GWR pollution. In these areas, once freed of the activities at risk, other activities considered "compatible" with the hydrogeological condition of the subsoil under consideration could be introduced.

\section{ACKNOWLEDGEMENT}

A grant issued by the European Social Fund (ESF) was used to carry out part of this study.

\section{REFERENCES}

AAVV., 2004. Final Report of COST ACTION, Vulnerability mapping for the protection of carbonate (Karst) Aquifers. EUR 20912, EUR Official Publication Office. http://www.argenco.ulg.ac.be/GEO3_Hydrogeolog ie/pdf/COST_620.pdf

Civita, M. and M. De Maio, 1997. Assessing Groundwater contamination risk using ARC/INFO via GRID function. Proceedings of 1997 ESRI User Conference, Publication GNDCI, S. Diego, California. http://proceedings.esri.com/library/userconf/proc97 /proc97/to600/pap591/p591.htm

Civita, M., 1990. Legend for map of unified vulnerability of groundwater. Unified legend for the aquifer pollution vulnerability maps. Studies on the vulnerability of aquifers, 1 (Annex), Pitagora Edit. Bologna, pp: 13.

Civita, M., G. Sappa and A. Zavatti, 2005. An evaluation practice for hazard sources of groundwater. IGEA, 20: 59-68.

Civita, M., M. de Maio, M. Farina and A. Zavatti, 2001. Guidelines for the preparation and use of cards of the vulnerability of aquifers to pollution. Manuali e linee-guida dell'ANPA, 4/2001 (Italian). http://www.apat.gov.it/site/_contentfiles/00038100/ 38186_manuali_2001_04.pdf 
Collin, M.L. and A.J. Melloul, 2001. Combined landuse and environmental factors for sustainable groundwater management. Urban Water, 3: 229237. DOI: $10.1016 /$ S1462-0758(01)00049-8

Collin, M.L. and A.J. Melloul, 2003. Assessing groundwater vulnerability to pollution to promote sustainable urban and rural development. J. Clean. Prod., 11: 727-736. DOI: 10.1016/S09596526(02)00131-2

Foster, S.S.D. and R. Hirata, 1988. Groundwater pollution risk assessment. A methodology using available data. http://www.cepis.opsoms.org/bvsacd/scan/020059.pdf

Foster, S.S.D., 2001. The interdependence of groundwater and urbanization in rapidly developing cities. Urban Water, 3: 185-192. DOI: 10.1016/S1462-0758(01)00043-7.

Haimes, Y.Y., 1984. Risk Assessment for the Prevention of Groundwater Contamination. NCR Studies Geophysics, Groundwater Contamination, ISBN: 0-309-03441-8, pp: 166-169.

Holman, D., 1958. Groundwater Potential Pollution Risk Assessment Index. In: Groundwater Protection Principles and Alternatives for Rock County, Zaporozec, A. (Ed.). Wisconsin, pp: 73.

Lashkaripour, G.R., 2003. Contamination of groundwater resource in Zahedan city due to rapid development. Pak. J. Applied Sci., 3: 341-345. DOI: $10.3923 /$ jas.2003.341.345
Nouri, J. and S. Malmasi, 2005. The role of groundwater vulnerability in urban development planning. Am. J. Environ. Sci., 1: 16-21. http://www.scipub.org/fulltext/ajes/ajes111621.pdf

Pfannkuch, H.O., 1990. Application of risk assessment to evaluate groundwater vulnerability to non-point and point contamination sources. Proceeding of the Atti $1^{\circ}$ USA/URSS Joint Conference on Environment Hydrology and Hydrogeological American Institute Hydrology, pp: 158-168.

RIVM and RIZA, 1991. Sustainable use of Groundwater. Problems and threats in the European Communities. Report no. 600025001. http://library.wur.nl/isric/index2.html?url=http://lib rary.wur.nl/WebQuery/isric/10073

Tacconi, E. and A. Zavatti, 1999. Relative pressure weighted indices of anthropogenic activities.

Wisconsin Groundwater Coordinating Council, 2002. Residential development and groundwater resources. Comprehensive planning and groundwater fact sheet 3 . http://www.dnr.state.wi.us/org/water/dwg/gw/pubs/ SmartGrowth3.pdf 